\title{
A Research on Job Satisfaction and Quality of Work Life of Women Officials in it/ Ites Sectors with Special Reference to Bengaluru City (Karnataka Stae)
}

\author{
E.Hemapriya, S. Ramachandran
}

\begin{abstract}
This paper is an exam of the consistence segment of business and the concept of running existence as an reputable noticed the woman within the discipline of advancement such data and organisation enabled (IT/ITES) component in Bengaluru, India. The ITES policy of Karnataka (2000) were anticipated in making Karnataka, normal ITES basis capital depending upon the place of work similarly because the potential of its pool of English speakme individuals. The town has infinite worldwide organizations (MNCs) with basic cutoff factors of the population works in these zones. This examination is the evaluation illuminating and signs and symptoms rely upon each the sizable and extra records. authentic real profile of women operating in IT/ITES in Bengaluru separated and the information is quantifiable try and renowned what delegates pleasant career has not anything to do with their inclination of work life. Estimations essentially within the idea of operating lifestyles, for instance, satisfactory reimbursement and practical, confirm and sound operating situations, probabilities to use and make as a long way as possible, the entryway open to continue with development and protection, social mixture within the commercial enterprise courting, constitutionalism in association paintings, paintings and best living space, social and working life precision likewise checked for this exam. The examination turned into guided by way of two studies questions. 1. What not unusual additives running lifestyles as located with the aid of the respondents? 2. If there's a connection between the idea of running existence and the pleasure of labor? assessment uncovered that there's a big connection among this action and the pride of work-lifestyles nature of women government within the districts referenced before. these revelations are the centrality of the principal definitive in mild of the fact that it allows the Human resources office for the assignment arrangement to enhance the operating life of the agent nature as for a diffusion within the delight of their physical activities. it is intended to help manufacturers with keeping apart systems inside the key problems of the operating surroundings to build up an approach for tending to this trouble.
\end{abstract}

Keywords: Quality of work life, job satisfaction, women officials, ITsector.

\section{INTRODUCTION}

In Nature of Quality work life (QWL) Has starting past due got strength within the instructional research. Its centrality has been basically harassed with the resource of HR chiefs inside the corporation world. more than one examinations have been conveyed in the sooner decade as an extended way lower back because the articulation

Revised Manuscript Received on September 14, 2019.

E.Hemapriya, Research Scholar, Department of MBA, Bharath Institute of Higher Education and Research, Chennai, Tamilnadu,India.

Dr.S. Ramachandran, Director,MM Institute of Management,MMDU University, Ambala, Haryana, India (E-mail: prakashvenkee07@gmail.com) "concept of labor existence" ended up definitely understood. Nadler and Lawler (1983) explicit that QWL has been considered in numerous conditions, and lately gathered electricity some of the boss and media. multiple examinations were driven on QWL after the perception changed into exhibited and located that the paintings lifestyles absolutely endorsed the people and their households (Lewis and Cooper, 1987; Kossek and Ozeki, 1998; Greenhaus and Powell, 2006). The humans get unfavorably impacted even as the work environment is fluctuating; this is contemplated as low motivation and remedy, low execution, decreased advantage and extended trimming down and burnout (Galinsky and Stein, 1990; Benedict and Taylor, 1995).

The prolonged dedication each at domestic and work has determined out the feebleness of the pro to alter the tough solicitations of circle of relatives and artwork including to prolonged weight and war inner present people (Edwards and Roth versifier, 2000). This internal warfare has in like manner achieved more than one restorative troubles in people and budgetary load on the people, chiefs and the company (Frone, Russell, and Cooper, 1997; Johnson, Duxbury, and Higgins, 1997). coastline (1975) and Walton (1975) conceptualized the concept of labor existence by offering 8 massive mind relating to QWL. those thoughts are (1) sensible and perfect compensation, (2) sound going for walks situations in the affiliation, (three) possibility to make human capacities, (four) opportunities for persevered with development and protection, (5) paintings relationship with social becoming a member of,.

The IT coverage 2002 of Karnataka articulates that the meeting will propel Karnataka as a preferred ITES purpose. The organisation has plans to make territory unequivocal shape offices, redress in actual and regulatory area work, making a top notch vicinity through propelling social exercises like organization prosperity organizations, veggies, all inclusive schools, information industry townships, fortifying of provincial ladies, and lots of others. The ITES coverage of Karnataka (2005) has a fable to make Karnataka the overall ITES capital. it's far normal that with the social, bodily and concrete system workplaces and a large pool of healthful, capable group of workers, Karnataka can remodel into the ITES capital. beneath those situations at the same time as the division itself has such an over 


\section{A RESEARCH ON JOB SATISFACTION AND QUALITY OF WORK LIFE OF WOMEN OFFICIALS IN IT/ ITES SECTORS WITH SPECIAL REFERENCE TO BENGALURU CITY (KARNATAKA STAE)}

whelming manual from the organisation because of its sizeable condition inside the economy, it's far vital to pay attention on its HR. From now on the girls dealers running in IT and ITES divisions in Bengaluru have been picked for the examination.

\section{Proclamation of problem}

career satisfaction consists of a distinguished pastime in every the life of a laborer and a dating as they all contributes for that simultaneously. because the monetary modifications in India, there may be a developing disparity to the extent socio-preservationist, highbrow and singular thriving maximum of the workers in the general amassing adventures and the unexpectedly growing information based organizations. those components require the evaluation on the segments contributing for the delegate pride and the consequent gainfulness in these types of organizations, wherein the workforce is inconceivably fluctuating with unique frames of thoughts and their perceptions about QWL.

\section{Objectives Of The Look At}

- to research the character of labor life and their determinants within the selected IT/ITES corporations.

- To measurethelevelofemployeesatisfactionandits determinants inside the selected IT/ITES organizations.

- To verify the representatives supposition at the organizationalpolicieswithrespecttocompensation, careerprospect,occupationalstressandparticipation inmanagement.

- $\quad$ to distinguish the regions that need improvement and to make pointers to improve the QWL inside the institutions understudy

\section{Extent Of The Examine}

"The present exam is planned to cowl the viewpoints giant for evaluating the employees (popularity diploma) feeling approximately the exceptional QWL ventures provided in their one among a kind affiliations. beginning at now referenced in this examination, the affiliations need to see the criticalness of creating occupations and working situations that might make sure the first-rate and productivity of the delegates, who ultimately will red meat up the connection to fulfill its agency targets.

The gift exam is anticipated to break up the elements which bring about excessive QWL in the present brisk making global and to reflect onconsideration on whether or not or no longer those elements change with reference to collecting and enterprise organisation quantities. The assessment will understand the QWL determine this is numerous within the amassing and organization fragments and the way it influences the specialist's flourishing. The aftereffect of the examination relies upon the inclination imparted by manner of the directors and government about QWL ventures passed on in their affiliations. The assessment further proposed to discover the covered elements within the back of excessive QWL in picked common collecting adventures and swiftly creating learning based help ventures.

\section{Research Hole}

loads of concentrates on the relationship among QWL and organisation associated additives are reachable. Scarcely any examinations communicate approximately simply the blessings of running in gatherings and the inclusion of the people in organizationaldesign. There are wide variety of appears into being directed on QWL, but there may be a good deal less research approximately the general achievement of representatives running in IT/ITES corporations inKarnatakaandthevariousfactors which have an impact at the QWL of humans in IT/ITES companies inKarnataka.

\section{METHODOLOGY}

The present study has adopted adescriptive and diagnostic design. The women executives included in the study were above 21 years of age,with a minimum of a year's work experience, working in administration, finance or HR department of organizations in the IT/ITES sectorin and around Bengaluru region.These women employees were called as executives as they were carrying out the administrative functions of the management. The study included 151 IT women employees and 70 ITES women employees.The list of companies was sourced from NASSCOM (National Association of Software and Service companies) and the companies were chosen randomly based on the vailability of the women employees.

assessment has attempted both emotional and quantitative estimations. quantifiable affordable instrument has been utilized to split the statistics accumulated via the systematized and composed the review. emotional framework as an inexpensive joint effort, remark, outside and inside the gathering and change easygoing get-together has comprehended the difficulty beneath scrutiny. A standardized gear referred to as task pleasure Scale became made by using Uppal and Dubey (1989) is utilized to test the level of pride of the career (alluded to in Pestonjee, 1995). A survey led relying upon Walton (1973) 8 determinants of QWL is applied to overview the QWL element. The facts is separated the use of SPSS.

full-size statistics amassed thru the mechanical assembly this is efficient and systematized girls received amongst government running in IT/ITES department are located in and around the neighborhood Bengaluru. extra statistics is accumulated from books, papers, web belongings, and journals. The assessment has 3 segments that include inquiries concerning the actual profile of the respondents, scale pleasure running with Uppal and Dubey (1989) and inquiries to check QWL relying upon the components of nature Walton working existence. The institutions chose discretionarily from NASSCOM shabby affiliation. The survey became turned around amongst three hundred respondents from 5 IT and ITES 5 associations in Bengaluru, via their specific HR division in mild of the truth that there are women who work around evening time to move too. $10 \%$ of the instance met through cellphone to transport greater facts on their operating life. round 250 surveys returned, of which 221 research were given seventy four\% makes the reaction rate. sorted out review relies upon on Walton (1973) estimations on the concept of operating 
lifestyles and moreover has initiated device on pleasurable paintings to produce statistics from respondents. association were given is based upon the capacity of respondents to look at the evaluation. regardless of the fact that the survey completed 221 receives indeed of respondents, an examiner related to $10 \%$ of the example of individuals to create greater statistics. The motive for this examination is to interrupt the authority authentic profile of girls running in IT/ITES internal and across the locale of Bengaluru; to understand the determinants of the idea of the working life of woman overseers in choosing the department; and to don't forget the level of satisfaction of the career a few of the directors in this female select quantities.

\section{Discoveries}

traits of Respondents records

The ladies respondents from the department have a spot to gather a few place within the age scope of 23 and forty five years. The everyday duration of respondents changed into 34 years. they've a gap with a lower level of responsibility is an individual engaged with the affiliation, the record and department dating to be increasingly specific HR humans who've been placed over the organization. Youths constructed up one hundred ten (half of), government of the focal diploma of eighty $(36 \%)$, and individuals in senior positions which $31(14 \%)$. girls in senior positions are not very many. This might be due to the weight associated with the movement, specifically popularity profession, conjugal and own family problems. It turned into seen that $70 \%$ of them can capably and $20 \%$ of them have a pivoting shift. fashions populace contains of $40 \%$ of wedded ladies with $30 \%$ of them have kids. The threat to blend, the threat to make capability, pay costs are sufficient and suitable, the sensibility of working hours has been gotten by way of a noteworthy quantity of respondents as a determinant of QWL.

\section{RESULTS}

Employment achievement amongst government women satisfaction of work of ladies government are assessed on an organized tool made through Uppal and Dubey (1989, alluded to in Pestonjee, 1995). It is predicated upon the 25 matters on a 5 -factor scale stretching out from unequivocal endorsement to solidly contradict this

Table 1

Level of job satisfaction

\begin{tabular}{lcc}
\hline Job satisfaction & $\begin{array}{c}\text { IT sector } \\
(\mathrm{N}=151)\end{array}$ & $\begin{array}{c}\text { ITES sector } \\
(\mathrm{N}=70 \\
(\%)\end{array}$ \\
\hline High job satisfaction & 75.1 & 65.4 \\
Moderate job satisfaction & 20.2 & 31.9 \\
Low job satisfaction & 04.7 & 02.7 \\
Total & 100 & 100 \\
\hline
\end{tabular}

Table1 show that $5 \%$ of the women executives in the IT sector and $65 \%$ of the women executives in the ITES sector had high level of job satisfaction.This finding is supported by the rising number of women employment in the section. We tested the hypotheses that there isno significant difference in job satisfaction among junior, middle and senior levels of women executives in the sector.

Kruskal Wallis test become carried out to appearance whether any substantial qualification existed in career delight among unique assignments. The p-estimation of the level of labor delight have become appeared as 0. 002. in this way the invalid speculation became rejected. this is there was an sizeable complexity within the diploma of employer delight many of the lesser, attention and senior levels of heads. The suggest function showed that lesser degree authorities had increasingly raised diploma of enterprise satisfaction (86. ninety) than interest diploma authorities (70. 27) trailed by way of senior degree authorities (fifty three. sixty eight).assignment and excellent of work existence in the IT area

It modified into conjectured that there's no critical differentiation on the QWL among junior, awareness and senior ranges of ladies executives in the detail. Kruskal Wall is take a look at on nature of labor life and venture, confirmed that the p-regard for QWL end up zero. 127 and changed into not essential at $1 \%$ degree. It possibly shows that there has been no essential qualification in the QWL of ladies authorities in exclusive assignments within the division.

\section{CONCLUSION}

The exam turned into restrained to girls executives in IT/ITES divisions in and across the Bengaluru area and thusly the effects cannot be summarized to numerous components. in any case, the disclosures issue towards the general mind-set on girls executives within the IT/ITES territory that may form the bottom for in addition research.

The examination ensures that there was a gigantic connection among's motion pride and nature of work lifestyles for delegates inside the IT/ITES department. Karnataka's purpose is to be a mechanical and IT popularity with its infrastructural and potential pool. Regardless, one have to now not dismiss the necessities of the paintings manage and the determinants that make their art work existence exceptional and gratifying. a blend of valid and proper duties makes it massive for the associations to design fitting sport plans for the worker's. that is important in moderate of the fact that a couple of factors related to affiliations like weight, and way of life provides to enthusiastic and execution associated problems for the staff. consequently it's far critical that noteworthy thought want to be paid to the additives that the marketers find out satisfying in their art work life. The disclosures of the evaluation are depended upon to make contributions in the direction of suggestions that could enhance the paintings lifestyles of girls executives

THE ACCOMPANYING suggestions ARE cautioned:

(a) creative evaluation structures to healthy the age and industrial organisation period of the delegates can satisfy their calling goals and assist their motion pride.

(b) the ones in the essential durations of calling are typically given weightage reliant on challenge finish whilst the ones at the senior tiers are assessed depending on electricity and capacity to get matters shifting. 
(c) inclusive of consciousness directors at some point of the time spent change can lower insurance from trade.

(d) Reclassifying occupations to wholesome the agent's delight and an evaluation of success can help within the development of the paintings lifestyles of the delegates.

(e) person tremendous sporting occasions software loosened as plenty as life accomplices can set off the collection of the delegates, to fathom the requirements of work.

(f) consultant help programs (EAP) can help people whose motion execution suffers due to physical, mental or excessive topics.

(g) The sexual direction differentials on profession satisfaction and nature of exertions existence need to be examined to bear in mind the impact at the branch even as all is stated in completed with the goal that the methodologies may be advanced as requirements be..

\section{REFERENCES}

1. Dwivedi, R.S. (2011).Human family members and OrganisationalBehaviour: A global angle. Bangaluru: McMillan Publishers India Ltd.

2. ElectronicsCorporationofKarnataka.(2008).Www.Elcot.I nAccessed5November 2013.

3. Governement of Karnataka IT coverage. (2002). Http://www.ItparkBangaluru.Com/insurance.HtmAccess ed5November2013.

4. authorities of Karnataka ITES policy. (2005). Http://www.ItparkBangaluru.Com/coverage.HtmAccesse d5November2013.

5. Hundekar, G.S. what is extra, Majeed, S.A. (2012) "factors of profession achievement among IT human beings: an examination." Southern Economist, 50(18): 20-23.

6. Kaila, H.L. (2005).Human useful resource control, Vol 1.New Delhi: Kalpaz guides.

7. Kumar, S. C. (2011). "profession stress and employment achievement of IT groups workers."

8. control and hard work research, 36(1): sixty one-70.

9. Kumar,H.V.AndPremchand,B.P.(2010)."Qualityofworkli feinITsector-Indian scenario."SRMManagementDigest,eight:a hundred and forty four-149.

10. Locke, E. (1976). 'the nature and motives for process success,' in M.D.Dumetti

11. (Ed.).Hand book of industrial and Organizational Psychology (pp.1297-1349).Illinois: Rand Mcnally.

12. Priya,S.(2012).'Motherhoodandqualityofworklifeofwome ninindustry.'http://www.Nasscom.In/places/default/recor ds/transfers/events2012/hr_summit/Motherhoodp.c2520a ndp.C2520qu.Accessed5November2013.

13. Walton,R.E.(1975).'Criteriaforqualityofworkinglife,'inL. E.DavisandA.BCherns(Eds.).TheQualityofWorkingLife, Vol2(pp.ninety one-104).NewYork:free Press. 